\section{Uso de fontes de pesquisa na escrita de artigos científicos de pesquisadores experientes}

Use of research sources in the writing of scientific articles by experienced researchers

Danielyson Yure de Queiroz VALENTIM (UERN) dvalentin123@hotmail.com José Evaristo de PAIVA NETO (UERN) evaristtonetto200o@gmail.com José Cezinaldo Rocha BESSA (UERN) cezinaldobessauern@gmail.com

Recebido em: 21 de fev. de 2020. Aceito em: 02 de jun de 2020.

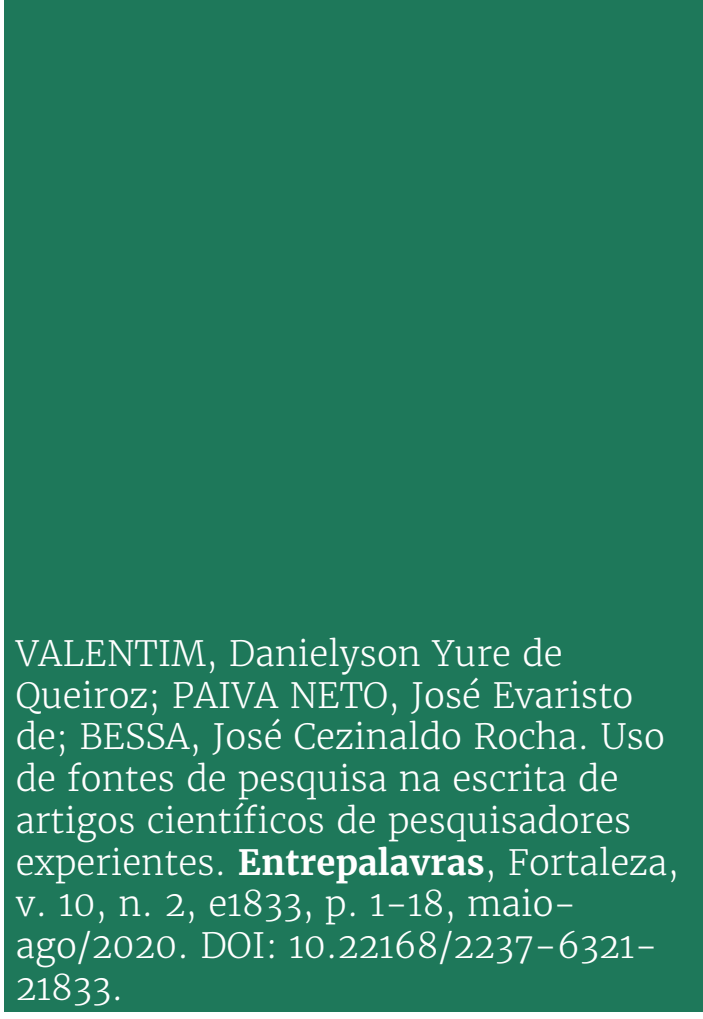

Resumo: Com a acelerada expansão das tecnologias digitais na nossa sociedade e sua presença/inserção no meio educacional e/ou acadêmico-científico, surge, no contexto universitário, uma preocupação quanto à capacidade de localizar, selecionar, avaliar, sintetizar e citar fontes externas na escrita científica, constituindo-se, pois, tal capacidade um elemento-chave do letramento acadêmico (BURTON; CHADWICK, 2000). Compartilhando dessa preocupação, buscamos, no presente trabalho, examinar como pesquisadores experientes mobilizam fontes externas na escrita dos textos científicos que produzem, focalizando, mais especificamente, aspectos como quantidade de fontes citadas, veículo de publicação, língua de publicação e ano de publicação. Fundamentados em trabalhos sobre letramento acadêmico, uso de fontes de pesquisa e práticas citacionais desenvolvidos por estudiosos como Burton e Chadwick (2000), Pecorari (2003, 2006, 2015), McClure e Clink (2009) e Howard, Serviss e Rodrigue (2010), dentre outros, realizamos uma análise descritivo-exploratória de um conjunto de 10 artigos científicos de pesquisadores experientes do domínio da 
V. $10(2)$

1-18 maio-ago 2020
Linguística coletados em um periódico científico dessa área. Os resultados indicam que a condição de expertise e a familiarização com práticas de letramento corroboram para que pesquisadores experientes revelem uma escrita científica (mais) ajustada, quanto à seleção e uso de fontes de pesquisa, a convenções estabelecidas no universo científico e em sua cultura disciplinar.

Palavras-chave: Uso de fontes. Letramento acadêmico. Pesquisadores experientes.

Abstract: : With the accelerated expansion of digital technologies in our society and their presence/insertion in the educational and/or academic-scientific environment, a concern arises in the university context regarding the ability to locate, select, evaluate, synthesize and cite external sources in scientific writing, thus constituting such a capacity as a key element of academic literacy (BURTON; CHADWICK, 2000). Sharing this concern, we aim, in the present study, at examining how experienced researchers mobilize their external research during the writing of the scientific texts they produce, focusing, more specifically, on aspects such as quantity of cited sources, publication vehicle, language of publication and year of publication. Based on works about academic literacy, use of research sources and citational practices developed by scholars such as Burton and Chadwick (2000), Pecorari (2003, 2006, 2015), McClure and Clink (2009) and Howard, Serviss and Rodrigue (2010), among others, we performed a descriptive-exploratory analysis of 10 scientific articles written linguists scholars who publish in journals in the field of Linguistics. The results indicate that the condition of expertise and familiarization with literacy practices corroborate for experienced researchers to reveal a (more) adjusted scientific writing, regarding the selection and use of research sources, to conventions established in the scientific universe and in its disciplinary culture.

Keywords: Use of sources. Academic literacy. Experienced Researchers.

\section{Introdução}

Com as possibilidades de ampliação, facilidade e conveniência quanto ao acesso a conteúdos que temos vivenciado no contexto da era digital, pesquisadores iniciantes e experientes vêm sendo desafiados em relação à necessidade de saber lidar com a multiplicidade de informações, com a avalanche de produções científicas e de saber selecionar fontes confiáveis no desenvolvimento de suas atividades de pesquisa. Nesse sentido, temos sustentado a defesa de que saber localizar, selecionar, avaliar, sintetizar e citar fontes externas são práticas consideradas como elemento-chave do letramento acadêmico (BURTON; CHADWICK, 2000).

Se as competências apontadas por Burton e Chadwick (2000), no começo do século XXI, poderiam ser vistas como um imperativo para pesquisadores iniciantes, da graduação e da pós-graduação, em seus escritos científicos, problematizar o uso de fontes também na escrita de pesquisadores com mais experiência de formação se mostra, cada vez mais, um debate frutífero, instigante e necessário. Isso se justifica quando levamos em consideração que vivemos a explosão da chamada cultura 
do open access e a multiplicação de práticas e produções suspeitas e/ou fraudulentas na ciência mundial, bem como o espantoso crescimento de periódicos vistos como predatórios ${ }^{1}$, nos quais os critérios de avaliação de manuscritos não costumam ser rigorosos, além de não prezarem pela qualidade da redação e da pesquisa empreendida.

Considerando, ademais, a acelerada expansão das tecnologias digitais na nossa sociedade e sua consequente presença/inserção no meio educacional e/ou acadêmico-científico, abrindo possibilidades de disseminação e uso de conteúdos nos mais variados formatos e plataformas digitais (MORAN, 1997; DEMO, 2009; BERNARDES; CATELÃO, 2016; LEFFA, 2017; BESSA; BERNARDINO, 2016; COSCARELLI, 2017; KERSH; MARQUES, 2017; ALVES; BESSA, 2018), despontam-se questionamentos e preocupações sobre a confiabilidade, a veracidade, o rigor e a autenticidade das fontes de pesquisa utilizadas também nas práticas de pesquisadores mais experientes.

Compartilhando, pois, dessa preocupação, buscamos aqui examinar como pesquisadores experientes mobilizam fontes externas na escrita de textos científicos que produzem. No recorte que constitui este trabalho, interessa-nos investigar, na escrita de artigos científicos da área de linguística, aspectos relativos ao uso de fontes considerados essenciais dentro dos letramentos acadêmicos na perspectiva defendida por Burton e Chadwick (2000). O foco recai especificamente no exame de aspectos como quantidade de fontes citadas, veículo de publicação da fonte citada, língua e ano de publicação.

Acreditamos que um estudo como este pode contribuir para provocar mais discussões acadêmicas, ainda bastante incipientes ou quase inexistentes no contexto brasileiro, sobre o uso de fontes de pesquisa na escrita científica, bem como possibilitar a necessidade de se pensar pedagogias mais eficazes, como suscitam McClure e Clink (2009) e Howard, Serviss e Rodrigue (2010), voltadas à proposição de intervenções que favoreçam o domínio do uso adequado e produtivo de fontes nas atividades de pesquisa e de escrita científica, especialmente de pesquisadores em início de carreira na graduação e na pós-graduação.

Motiva-nos, pois, a expectativa de que esta investigação possa oferecer importantes elementos para se conceber o ensino e a instrução quanto ao uso de fontes no trabalho com jovens pesquisadores. Logo,

${ }^{1}$ O jornal Pesquisa FAPESP, em matéria de agosto de 2018, intitulada A sombra das revistas predatórias no Brasil, sinaliza o espaço que esse tipo de veículo suspeito e indesejável começa a ocupar na publicação científica de pesquisadores nacionais. Disponível em: https://revistapesquisa.fapesp. br/2018/08/09/a-sombra-das-revistas-predatorias-no-brasil/.Acesso em: 14 fev. 2020. 
V. $10(2)$

1-18

maio-ago

2020

acreditamos que ações pedagógicas podem ser melhor direcionadas a partir do nosso conhecimento das práticas e experiências daqueles que são considerados pesquisadores bem-sucedidos em seus escritos de pesquisa, com as quais os jovens pesquisadores podem se familiarizar de modo mais efetivo quando instruídos por meio de um trabalho de mediação docente conduzido de maneira sistemática e bem orientada.

\section{Ancoragens teóricas}

Em decorrência do avanço significativo dos recursos tecnológicos e da grande quantidade de conteúdos sobre ciência disponíveis na internet em nossos dias, utilizados tanto por pesquisadores experientes como por pesquisadores iniciantes, as práticas de escrita na universidade têm despertado cada vez mais interesse e têm sido problematizadas, especialmente, quanto ao desafio de se fazer uso adequado e pertinente de fontes de pesquisa confiáveis e de se obter informações de qualidade (SANCHEZ; WILEY; GOLDAM, 2006). Muitos estudiosos (BURTON; CHADWICK, 2000; MCCLURE; CLINK, 2009; dentre outros) têm se dedicado a investigar as práticas de seleção e uso de fontes por estudantes em formação, focalizando, por exemplo, o exame de critérios de seleção, tipos e padrões que corroboram para a utilização de fontes de pesquisa confiáveis e de credibilidade em trabalhos científicos.

As inquietações, que mobilizam pesquisadores como Burton e Chadwick (2000), Mcclure e Clink (2009), Howard, Serviss e Rodrigue (2010), Jamieson (2017) e Rodrigue (2017), situam-se dentro de perspectivas de investigação que têm se interrogado a respeito dos letramentos acadêmicos no universo digital próprio de nosso tempo, enfatizando a capacidade de "localizar, selecionar, avaliar, sintetizar e citar fontes externas em sua própria redação"2 (BURTON; CHADWICK, 2000, p. 309). Tais investigações apontam que tal capacidade de reconhecer fontes confiáveis é um valioso instrumento de conhecimento científico face o número expressivo e diversificado de informações irrelevantes e enganosas presentes na rede de internet, bem como dada a constatação de que estudantes tendem tanto a usar apenas a internet como fonte de pesquisa quanto a fazer seleção aleatória de fontes para emprego em seus textos científicos (MCCLURE; CLINK, 2009).

${ }^{2}$ Original em inglês: "[...] the ability to locate, select, evaluate, synthesize, and cite outside sources in their own writing." 
McClure e Clink (2009) salientam, inclusive, a necessidade de seleção das fontes por parte dos pesquisadores independentemente do nível de formação em que esses se encontrem. Reportando-se ao que expressa a Association of College and Research Libraries, os autores afirmam que "[...] o aluno instruído em informação examina e compara informações de diversas fontes, afim de avaliar confiabilidade, validade, precisão, autoridade, pontualidade e ponto de vista ou viés" 3 (MCCLURE; CLINK, 2009, p. 116). Sendo assim, é evidente que as capacidades mencionadas por Burton e Chadwick (2000) compõem um elemento fundamental não só para uma escrita científica de qualidade, mas também para uma aprendizagem bem-sucedida (SANCHEZ; WILEY; GOLDAM, 2006).

Por apresentarem trajetória acadêmica já constituída no que diz respeito a nível de conhecimento e domínio de convenções e práticas da esfera científica e de sua cultura disciplinar 4 , é comum que pesquisadores experientes demonstrem uma capacidade mais crítica para lidar com as fontes de pesquisa em seus escritos, possibilitandolhes fazer uso de critérios que resguardem a confiabilidade, a precisão e a adequação das fontes citadas. É nessa direção que sinaliza a seguinte afirmação de Goldman et. al. (2012, p. 357): "quando especialistas leem artigos em seu campo para avançar sua própria compreensão de um fenômeno, eles consideram explicitamente a confiabilidade das fontes de informações $[\ldots]$ "...

Além disso, consideramos que a expertise que caracteriza o pesquisador experiente é fundamental para que ele possa fazer uso apropriado das fontes em seus textos científicos, como depreendemos dos posicionamentos de Bazerman (2014) e Bessa (2016). Em outras palavras, podemos compreender que, a partir da familiarização às práticas de letramento e às experiências em suas culturas disciplinares, pesquisadores experientes levem em conta critérios como tipo de fonte

\footnotetext{
3 Original em inglês: "“The information literate student examines and compares information from various sources in order to evaluate reliability, validity, accuracy, authority, timeliness, and point of view or bias".

${ }^{4}$ Embora dialoguemos com trabalhos que pensam a escrita científica de acordo com as culturas disciplinares, assumimos (BESSA, 2016) a compreensão de que, no estudo de textos científicos, é essencial considerarmos, por exemplo, as especificidades das condições concretas de produção, recepção e circulação do texto (por isso escolhemos uma revista específica) e o estatuto do produtor na atividade científica (por isso a escolha por pesquisadores considerados experientes), aspectos que, a nosso ver, ajudam a compreender melhor as práticas nas culturas disciplinares.
}

${ }^{5}$ Original em inglês: "When experts read articles in their field to advance their own understanding of a phenomenon, they explicitly consider the reliability of the information sources $[\ldots]$ ". 
V. $10(2)$

1-18

maio-ago

2020

utilizada, autoridade da fonte, atualidade, viés assumido pelo autor da fonte citada, dentre outros, os quais nem sempre são considerados por estudantes, conforme indicam McClure e Clink (2009).

Embora os estudos sobre uso de fontes estejam, no mais das vezes, centrados nas práticas de pesquisa e de escrita de estudantes, especialmente universitários, é pertinente ponderar que vivemos num contexto em que são cada vez mais recorrentes trabalhos (DINIZ; TERRA, 2014; PECORARI, 2003, 2006, 2015; PECORARI; PETRIĆ, 2014; BATTESTIN; DUTRA, 2019) relacionando muitos casos de plágio ${ }^{6}$ (tão recorrentes no meio acadêmico-científico) não somente às dificuldades de escrita daqueles, mas também às más condutas de pesquisadores experientes. Nesse sentido, é prudente considerar o exame das práticas de pesquisadores experientes quanto ao manuseio dos tipos de fontes (citação literal, paráfrase, patchwriting, plágio) descritos por Howard, Serviss e Rodrigue (2010), dentre outros aspectos (ver, por exemplo, PINTO, 2018; BERNARDINO; NASCIMENTO; QUEIROZ, 2018) que constituem o fazer científico.

Quando se discute, portanto, o diálogo com fontes de pesquisa e seu uso nas práticas acadêmicas, muitas outras questões complexas e nuances entram em cena e precisam ser observadas por pesquisadores e professores universitários, sobretudo, pela necessidade de desenvolvermos trabalhos de orientação e ensino voltados à superação de problemas de uso de fontes que as pesquisas desenvolvidas até aqui têm diagnosticado (ver RODRIGUE, 2017; JAMIESON, 2017, dentre outros). Afinal, parece-nos que, em nossos dias, "é um imperativo saber selecionar informações pertinentes que possam nos ajudar a construir reflexões bem fundamentadas"7 (NAVARRE, 2020, s. p.).

\section{Metodologia}

A proposta de investigação aqui empreendida se configura como uma pesquisa de natureza descritivo-exploratória e de abordagem qualitativa seguindo o entendimento de Laville e Dionne (1999). Dada a compreensão, apoiada em André (1995), de que a dimensão quantitativa ajuda na elucidação de um olhar qualitativo, este estudo lança mão

\footnotetext{
${ }^{6}$ Não podemos deixar de considerar que, no universo acadêmico-científico, fale-se de uma "epidemia de plágio" como reflexo de uma "cultura da trapaça", um problema relativamente comum entre pesquisadores experientes.
}

7 Original em francês: "Il faut savoir sélectionner les informations pertinentes qui peuvent nous aider à construire des réflexions bien fondées". 
também de dados quantitativos, com vistas a dar mais sustentação à análise de natureza exploratório-descritiva que, neste momento, buscamos fazer de um corpus selecionado de um banco de dados utilizado em nossas pesquisas, no Grupo de Pesquisa em Produção e Ensino do Texto (GPET), da Universidade do Estado do Rio Grande do Norte.

Para os propósitos deste trabalho, recortamos um corpus com 10 textos do gênero artigo científico publicados por pesquisadores que atendam ao nível de formação estabelecido, no caso pesquisadores experientes, da área de linguística. Nesse sentido, tais textos foram coletados na revista Linguagem em (Dis)curso, que é um periódico brasileiro da área de Linguística especializado em questões relativas ao campo textual-discursivo. Esse periódico está classificado com o estrato A1 no Webqualis da área de Linguística e Literatura na avaliação da Coordenação de Aperfeiçoamento de Pessoal de Nível Superior (CAPES) referente ao período de 2013-2016, constituindo-se um periódico de referência na área.

Para a caracterização do perfil dos pesquisadores experientes, estabelecemos os seguintes critérios: i) ter titulação de doutor há, no mínimo, 10 anos; ii) ser docente vinculado à programa de pós-graduação stricto sensu; iii) apresentar, pelo menos, 5 orientações de mestrado ou doutorado concluídas; iv) apresentar, pelo menos, 20 publicações relevantes em periódicos e/ou livros na área de formação.

Com vistas à verificação dos critérios relativos ao perfil de cada pesquisador/autor dos artigos recortados como corpus da pesquisa, utilizamos como recurso a consulta ao currículo disponível na Plataforma Lattes do Conselho Nacional de Desenvolvimento Científico e Tecnológico (CNPq), para obter mais informações além daquelas apresentadas, pelos autores, nos próprios textos coletados.

Como procedimentos de coleta e análise dos dados, adotamos o seguinte percurso investigativo: i) identificação, a partir do Qualis/ CAPES, de periódicos que se enquadrassem dentro da proposta da pesquisa; ii) consulta para obtenção de informações, nas páginas dos periódicos selecionados, com vistas a identificar aqueles que atendiam ao perfil de publicação de textos de pesquisadores experientes; iii) seleção do(s) artigos científicos que comporiam o corpus da pesquisa seguindo os critérios estabelecidos; iv) codificação ${ }^{8}$ dos artigos selecionados; v)

\footnotetext{
${ }^{8}$ Os artigos do corpus desta pesquisa foram codificados com a seguinte identificação: ACE01, ACO2 e assim por diante, em que AC corresponde a Artigo Científico, E designa Experiente e os numerais 01 e 02 correspondem à ordem numérica, estabelecida aleatoriamente, dos textos selecionados.
} 
V. $10(2)$

1-18

maio-ago

2020

leitura e releitura dos artigos científicos selecionados como corpus da pesquisa, para posterior interpretação e análise, em conformidade com os objetivos da pesquisa e com a literatura delimitada; vi) realização de uma análise qualitativa do corpus, focalizando a descrição, a análise e a interpretação dos aspectos sobre uso de fontes definidos para estudo neste trabalho.

\section{Análise e discussão dos resultados}

Nesta seção do trabalho, concentramos a atenção na análise de textos científicos produzidos por pesquisadores experientes da área de linguística, de modo a identificar como as fontes externas são mobilizadas na escrita desses textos. Nossa análise contempla o exame de alguns aspectos específicos relacionados ao uso de fontes na escrita de artigos científicos tais como: quantidade de fontes citadas, veículo de publicação da fonte citada, língua de publicação e recência da publicação.

Considerando a compreensão de que o diálogo com múltiplas fontes de pesquisa num processo investigativo (COSCARELLI, 2017) contribui para o aprofundamento das reflexões empreendidas em um trabalho científico e para a persuasão acadêmica (HYLAND, 2009; LATOUR, 2000), interessamo-nos por verificar a quantidade de fontes que os pesquisadores experientes mobilizam em seus escritos.

No gráfico a seguir, podemos observar a quantidade de fontes citadas em cada um dos 10 textos examinados.

Gráfico 1 - Quantidade de fontes citadas por pesquisadores experientes

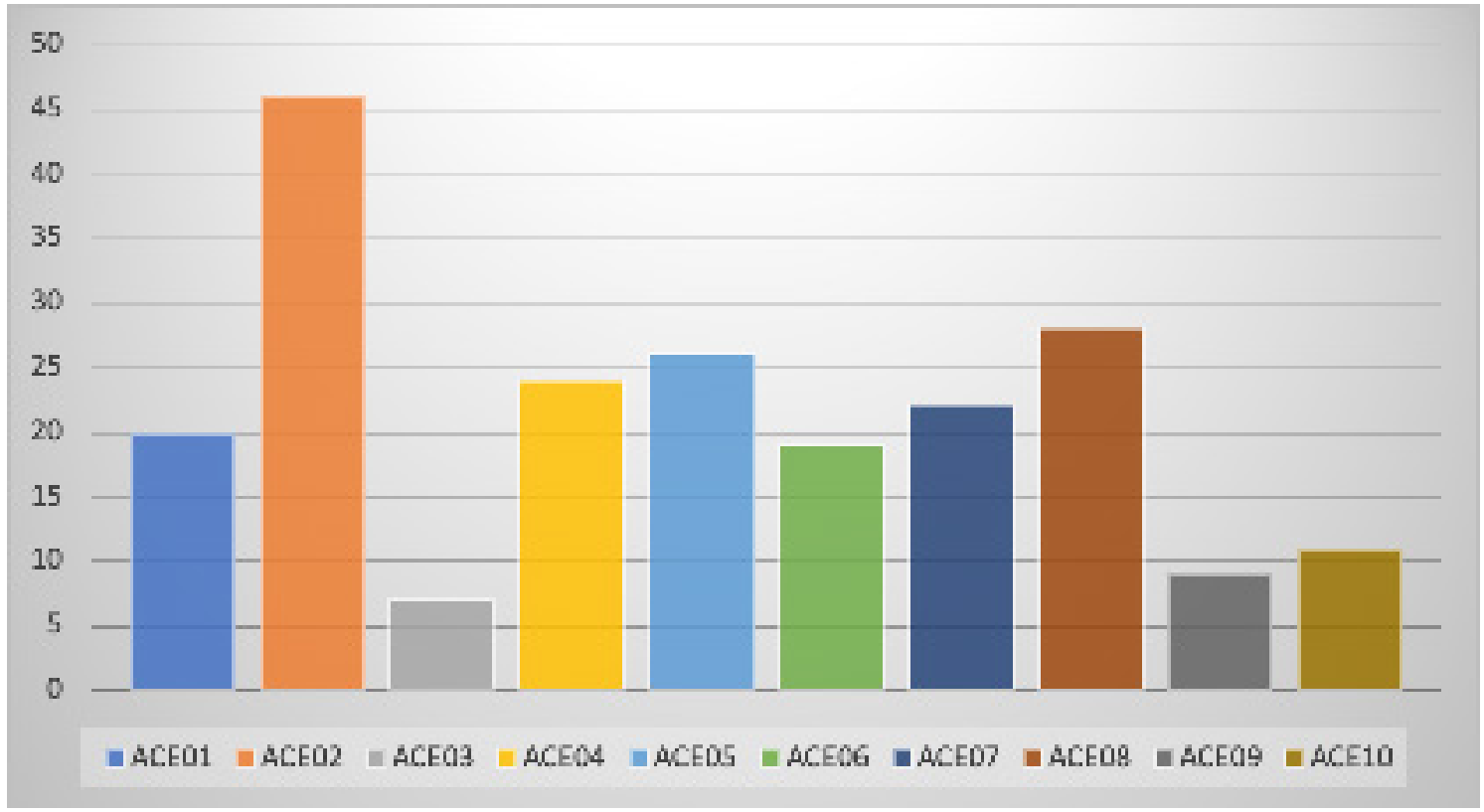

Fonte: Dados de pesquisa dos autores. 
Podemos observar que, embora 3 pesquisadores façam uso de menos de 10 fontes de pesquisa em seus escritos, a maioria deles, mais precisamente 6 , se reporta a 20 ou mais trabalhos de pesquisa, o que sinaliza que parte expressiva dos pesquisadores experientes do contexto investigado demonstra dialogar com uma quantidade considerável de fontes externas na construção de seus trabalhos de pesquisa. Isso aponta para o fato de que um artigo científico amparado em múltiplas fontes, adequadamente selecionadas, tende a contribuir para a construção de um texto científico bem fundamentado teoricamente e para a persuasão acadêmica (HYLAND, 2009; LATOUR, 2000), além, claro, de satisfazer a dimensão intertextual que se dá por meio do gerenciamento de múltiplas vozes em sua argumentação (BOCH, 2013).

Também relacionado ao aspecto anterior, a origem/veículo das fontes citadas pelos autores em seus textos foi questão de interesse em nossa pesquisa, considerando que, de acordo com McClure e Clink (2009), esse aspecto é de fundamental importância quando se pensa a questão da credibilidade e confiabilidade das fontes citadas. Até porque também, conforme depreendemos de Volpato (2010), determinadas fontes carecem de respeitabilidade científica, já que não passam pelo crivo de um sistema (rigoroso) de revisão/avaliação por pares. Nesse sentido, apresentamos, no gráfico 2, a postura dos pesquisadores experientes quanto a esse aspecto do uso de fontes em seus escritos científicos.

Gráfico 2 - Origem das fontes citadas por pesquisadores experientes

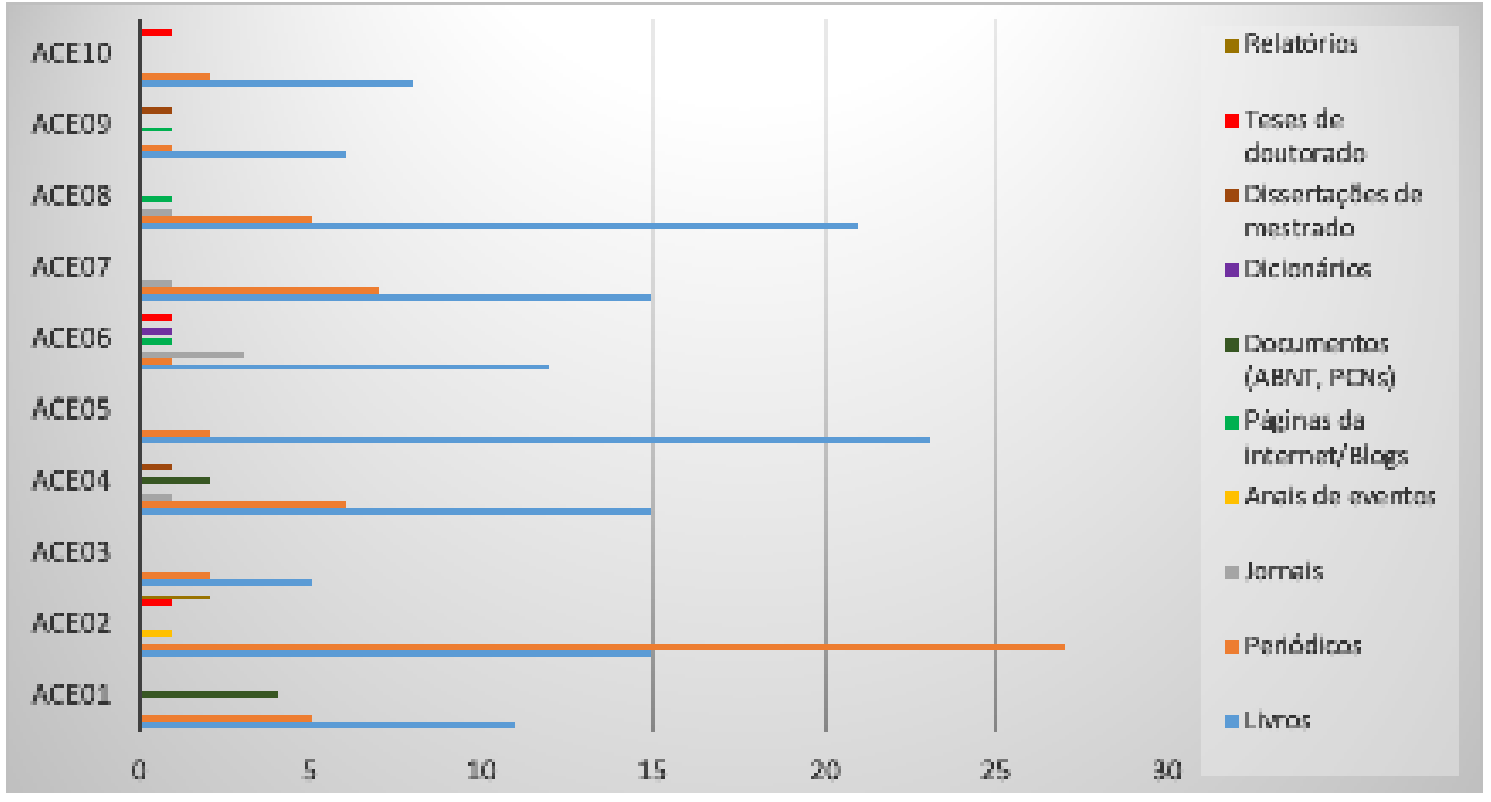

Fonte: Dados de pesquisa dos autores. 
V. $10(2)$

1-18

maio-ago

2020

Podemos perceber, no gráfico, que os pesquisadores experientes se utilizam de uma variedade de fontes de pesquisa, incluindo, dentre eles, relatórios, dissertações de mestrado, teses de doutorado, páginas de internet e anais de eventos, para fundamentar seus escritos. Aqui é preciso considerarmos, por exemplo, que citar páginas de internet e anais de eventos se configura como uma prática que, via de regra, não costuma ser recomendada e/ou aceita pela comunidade científica, já que essas fontes nem sempre são consideradas confiáveis e credíveis (BURTON, CHADWICK, 2000; MCCLURE, CLINK, 2009).

Observamos, ademais, que, no conjunto dos 10 artigos recortados, predomina o uso de fontes de pesquisa de livros e periódicos. Embora, na comunicação científica de diversas áreas do conhecimento, os periódicos científicos sejam considerados os veículos por excelência da divulgação do saber, podemos constatar que entre os pesquisadores experientes da área de Linguística do contexto investigado ainda predominam, em 90\% dos textos, os livros como fontes de pesquisa. A única exceção é, pois, ACE02, em que o número de trabalhos de periódicos é bem superior ao de livros.

Constatamos que as fontes oriundas de periódicos ocupam um espaço relativamente baixo quando comparadas àquelas de livros, constatação que se encontra em consonância com resultados do trabalho de Pacheco, Abreu e Bernardino (2018) sobre o uso de referências na cultura disciplinar da área de linguística. Esses dados parecem ser reflexo ainda de uma cultura, assinalada por Fiorin (2007), própria do campo das Ciências Humanas, Ciências Sociais Aplicadas, Letras, Linguística e Artes, de se propagar as produções por meio de livros e capítulos de livros. Não é difícil reconhecer, entretanto, que essa prática de socializar a produção científica da área ${ }^{9}$ venha se modificando, nos últimos anos, com a cultura do acesso aberto e a lógica de valorização, no Webqualis da CAPES, das publicações em periódicos.

Uma questão importante acerca de uso de fontes de pesquisa e que podemos relacionar às possibilidades de ampliação das referências

\footnotetext{
${ }^{9}$ Ainda que se refiram não especificamente à área de Linguística, os números da produção intelectual de docentes vinculados à pós-graduação stricto sensu brasileira apresentados, em 2019, no Relatório de Meio Termo da Área de Linguística e Literatura, da CAPES, indicam que, mesmo diante uma forte presença de publicações em periódicos, predominam as publicações em livros e capítulos de livros: "No cômputo geral da publicação em periódicos, nos anos de 2017 e 2018, os docentes da área publicaram 8746 artigos em periódicos de A1 a A4. Quanto à produção e livros, em 2017 e 2018, os docentes da Área publicaram 3642 obras (incluindo livros autorais e coletâneas) e $\mathbf{1 0 0 6 2}$ capítulos" (2019, p. 9, grifo nosso). Disponível em: http://www.uab.capes.gov.br/avaliacao/sobre-as-areas-de-avaliacao/74-dav/caa2/4675linguistica-literatura. Acesso em: 18 abril 2020.
} 
mobilizadas em um texto científico diz respeito à língua/idioma em que ele é publicado. Compreendemos que, em um contexto de globalização da ciência (VOLPATO, 2010), que valoriza as redes de colaboração internacional e interliga pesquisadores em diferentes centros de pesquisa mundialmente, a capacidade de ler produções científicas publicadas em diferentes línguas representa a possibilidade de benefícios enormes para o enriquecimento das reflexões e contribuições que um trabalho de pesquisa pode vir a apresentar ou mesmo para a decisão de levar adiante ou não um empreendimento investigativo, conforme sinaliza Eco (2014). Com isso em vista, procuramos saber as línguas dos textos de pesquisas citados nos escritos de pesquisadores experientes da área de Linguística do contexto investigado. Os resultados referentes a esse aspecto do uso de fontes de pesquisa constam no gráfico a seguir:

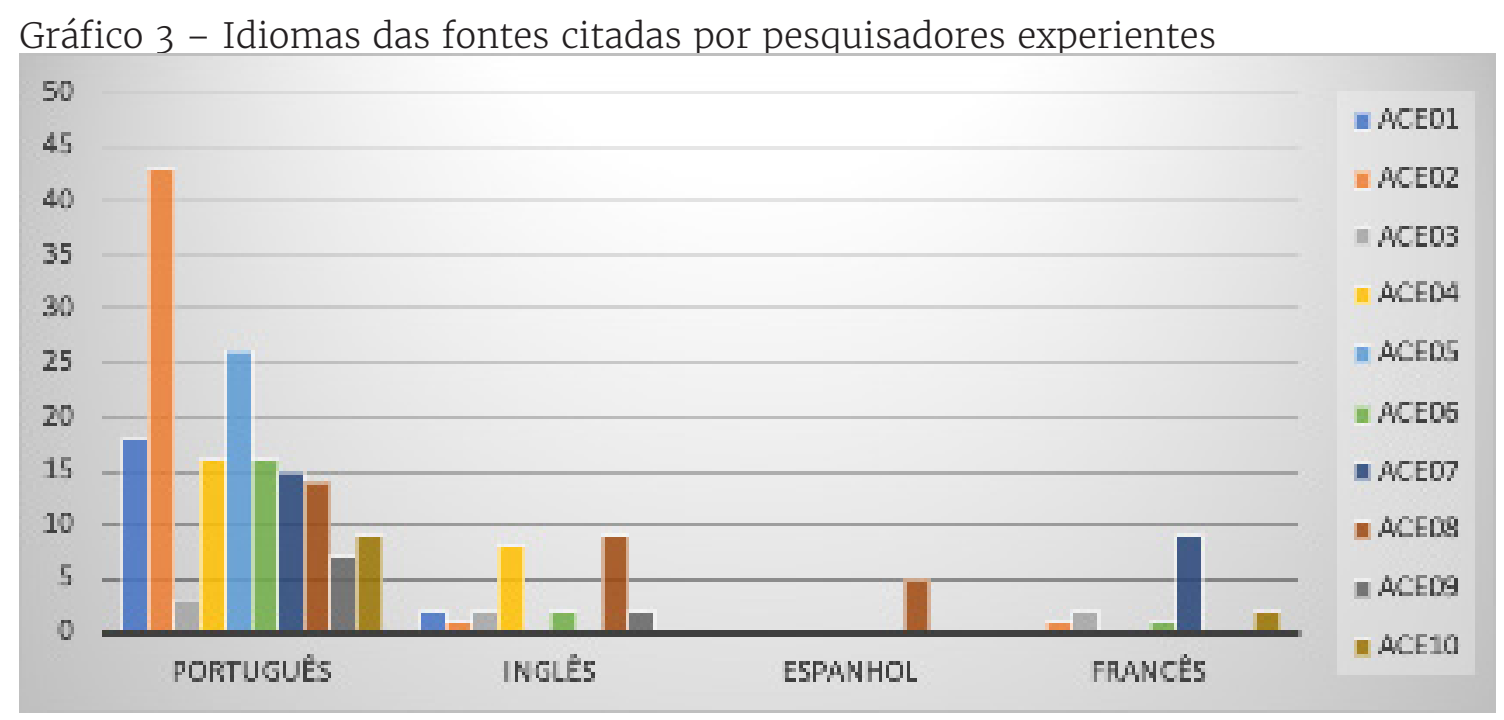

Fonte: Dados de pesquisa dos autores.

O gráfico 3 mostra que a maioria dos pesquisadores experientes da área de linguística do contexto investigado se reporta a fontes publicadas em mais de uma língua. Dos 10 textos do nosso corpus, verificamos que somente ACE05 cita apenas textos publicados em português, sendo que os demais citam em, pelo menos, duas línguas, dentre as quais o português. Podemos constatar que 04 se reportam a textos publicados em 03 línguas, incluindo o português.

Embora em determinadas áreas do conhecimento, como é o caso das ciências biológicas e exatas (cf. VOLPATO, 2010), o inglês seja a língua da ciência e os textos publicados nessa língua prevaleçam como fonte de pesquisa, o gráfico 3 permite perceber que, na área de Linguística do contexto pesquisado, predomina, nos 10 textos do corpus, 
V. $10(2)$

1-18

maio-ago

2020

a citação de fontes publicadas em português. Já os textos publicados em inglês são fonte em 07 dos artigos por nós examinados. Porém, fica evidente que há uma incorporação ainda relativamente baixa de produções em língua inglesa como fonte de pesquisa desses trabalhos.

Chama atenção que os textos publicados em francês sejam fontes de pesquisa de 05 dos artigos de nosso corpus, sendo em alguns casos mais citados que aqueles em língua inglesa, o que pode ser justificado pela inclinação do diálogo entre os estudos do texto e do discurso desenvolvidos no Brasil com aqueles realizados na França. É, além disso, surpreendente que apenas um dos artigos do corpus, (ACE08), tenha citado fonte publicada em espanhol.

Esses dados apontam que é comum a presença de fontes publicadas não apenas em língua portuguesa, mas também em outras línguas como inglês, francês e espanhol, sendo mais recorrente cada pesquisador citar produções publicadas em pelo menos 3 línguas distintas, incluindo português. Isso indica que, ainda que a maioria interaja com fontes de pesquisa de outras línguas, os pesquisadores experientes do contexto pesquisado tendem a dialogar mais com as produções científicas publicadas em português, que são resultantes, no mais das vezes, de pesquisas nacionais. Tal constatação sinaliza, pois, que há espaço para estabelecimento de maior interlocução com pesquisas de outros países, inclusive de países vizinhos que tem o espanhol como língua oficial, de modo a expandir as redes de interação com a ciência praticada internacionalmente, bem como permitir uma internacionalização da educação e um maior intercâmbio científico (FINARDI; FRANÇA, 2016).

Esteve ainda como foco de interesse de nosso trabalho averiguar o aspecto da atualidade das fontes de pesquisas que foram citadas nos artigos científicos recortados. Esse interesse se justifica pelo fato de que se reportar a trabalhos recentes é elemento bastante valorizado no universo da comunicação científica (MOTTA-ROTH; HENDGES, 2010), sendo apontado, geralmente, como um critério decisivo para a escrita de um artigo científico de qualidade (PEREIRA, 2012) e sua publicação em periódicos. O gráfico a seguir apresenta os resultados referentes a este último aspecto por nós focalizado. 
Gráfico 4 - Recência das fontes citadas por pesquisadores experientes

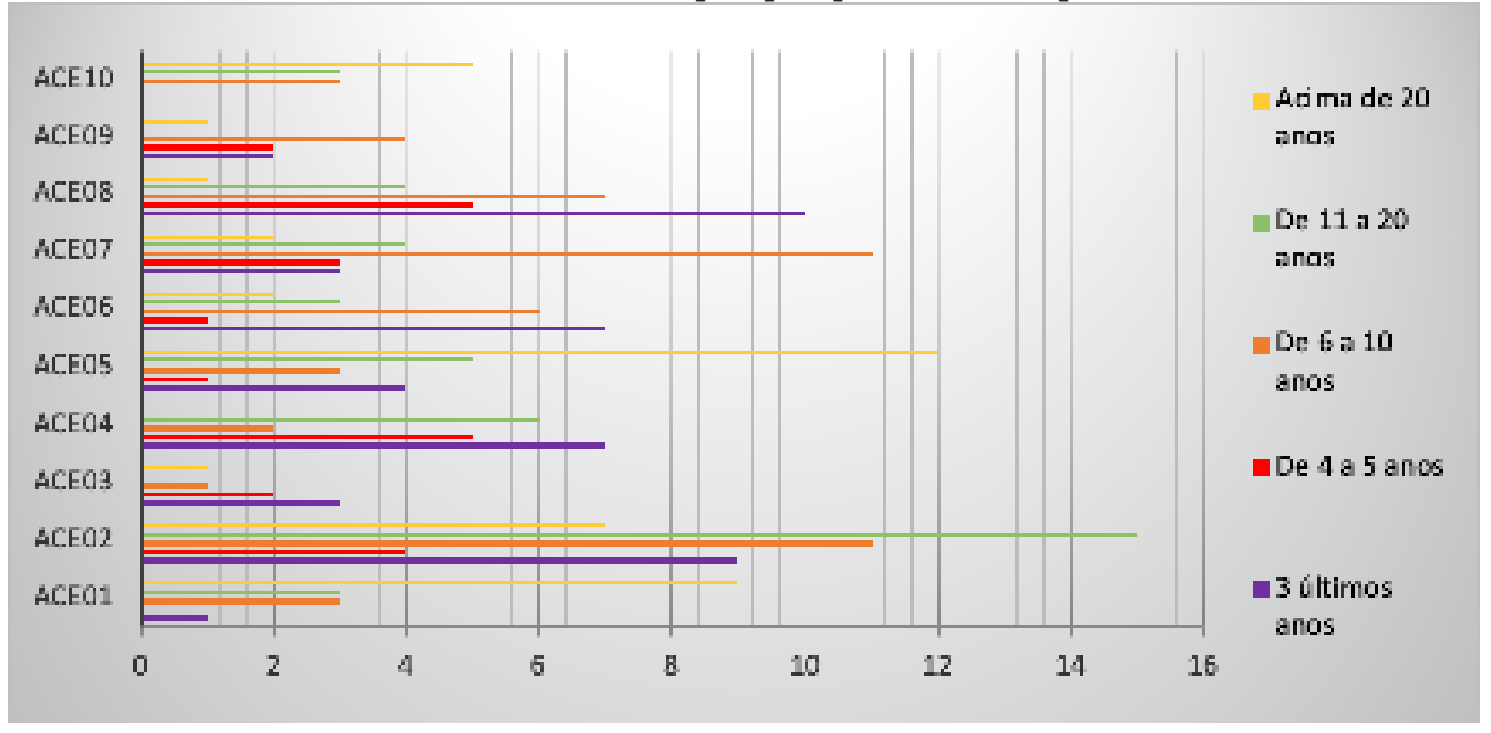

Fonte: Dados de pesquisa dos autores.

Como vemos no gráfico, examinamos o aspecto da recência das fontes citadas com base no estabelecimento de 5 categorias, sendo que projetamos, em um polo, até 3 anos como parâmetro de uma fonte muito atualizada, e em outro polo, acima de 20 anos, como pouco atualizada. Nosso exame apontou que há um certo equilíbrio, nas 5 categorias, quanto ao ano/período de publicação das fontes de pesquisa citadas. Verificamos aí que as fontes dos últimos 3 anos são aquelas predominantes em apenas 03 dos artigos (ACE03, ACE06 e ACE08) do corpus. É curioso constatar que fontes de acima de 20 anos são as predominantes também em 03 artigos (ACE01, ACE05 e ACE10). Podemos observar, pois, que a predominância de um ou outro período de tempo de publicação se dá mais de artigo para artigo e não indica algum padrão quanto à postura dos pesquisadores quando se trata da seleção das fontes no que tange ao aspecto da sua recência ou não.

Se para determinadas áreas do saber há um imperativo de que se deve citar um percentual relativamente elevado de fontes atualizadas, preferencialmente dos últimos cinco anos, os dados de nossa pesquisa apontam que, na área de Linguística, os pesquisadores experientes mesclam suas fontes de pesquisa tanto com textos mais atualizados quanto com fontes mais antigas. Isso vai ao encontro do que pontuam Motta-Roth e Hendges (2010), quando dizem que o aspecto da recência pode adquirir mais importância conforme as áreas e disciplinas assumam uma tendência de valorizar ou não o saber acumulado ao longo do tempo. 
V. $10(2)$

1-18

maio-ago

2020

Os dados analisados permitem, pois, perceber que, quanto ao ano de publicação das fontes citadas, quase todos os pesquisadores experientes costumam citar tanto textos recentes, publicados nos últimos 3 anos, quanto textos mais antigos, com período de publicação acima de 20 anos. Isso mostra uma preocupação desses pesquisadores de dialogarem com produções atualizadas e referências mais clássicas nas temáticas pesquisadas, o que é uma postura bastante salutar, considerando que, na área da Linguística, tão quanto os trabalhos considerados clássicos, as produções científicas mais recentes não necessariamente precisam ser ignoradas, sobretudo quando se tem em vista que o avanço na construção do conhecimento implica considerar o diálogo com as produções mais recentes dos seus pares (BESSA, 2017). Além disso, como pontua Volpato (2010, p. 106), é fundamental citar "autores que iniciaram uma ideia. Mas, como geralmente são obras antigas, acrescente literatura recente [...]" como estratégia de validação das fontes mais antigas com a inclusão de referências atualizadas.

É possível percebemos que os pesquisadores experientes do contexto investigado demonstram, em geral, fazer seleção e uso de fontes de pesquisa em seus escritos de maneira pertinente e produtiva. Sem entrar no mérito de questionar a qualidade do texto, podemos pensar que um aspecto que mereça ponderação seja a interlocução com fontes de pesquisa publicadas em outras línguas, com cujo diálogo as pesquisas poderiam se enriquecer, à medida que expandiriam suas possibilidades de leituras e potencializariam o aprofundamento das reflexões e contribuições científicas.

\section{Conclusão}

Neste trabalho, nosso propósitofoi examinarcomopesquisadores experientes da área de linguística dialogam com as fontes de pesquisas que mobilizam na escrita dos textos científicos que produzem, focalizando aspectos como quantidade de fontes citadas, veículo de publicação da fonte citada, língua de publicação e ano de publicação.

Fundamentados em trabalhos sobre letramento acadêmico, uso de fontes de pesquisa e práticas citacionais de estudiosos como Burton e Chadwick (2000), Pecorari (2003, 2006, 2015), McClure e Clink (2009) e Howard, Serviss e Rodrigue (2010), desenvolvemos uma análise descritivo-exploratória de um corpus constituído por 10 artigos científicos de pesquisadores experientes da área de linguística. 
Os resultados da investigação empreendida apontam que: i) os pesquisadores experientes estabelecem diálogo com múltiplas fontes de pesquisa na construção de seus escritos; ii) os pesquisadores do contexto investigado recorram a fontes de pesquisa variadas para produzir seus escritos, sendo que a maioria delas é oriunda de livros e periódicos, prevalecendo ainda uma cultura do diálogo com livros; iii) é comum a presença de fontes publicadas não apenas em língua portuguesa, mas também em outras línguas como inglês, espanhol e francês, indicando que, em meio a uma abertura para o intercâmbio de ideias com pesquisas internacionais, prevalece uma tendência de diálogo mais estreito com a literatura científica nacional; iv) quase todos os pesquisadores do contexto investigado costumam citar tanto textos recentes, publicados nos últimos 3 anos, quanto textos mais antigos, com período de publicação acima de 20 anos, o que mostra uma preocupação de dialogarem com produções atualizadas e referências mais clássicas nas temáticas pesquisadas.

Esses resultados indicam que a condição de expertise e a familiarização com práticas de letramento corroboram para que os pesquisadores experientes do contexto investigado revelem uma escrita científica (mais) ajustada, quanto à seleção e utilização de fontes de pesquisa, a convenções estabelecidas no universo científico e em sua cultura disciplinar.

Cumpre-nos destacar, por fim, que esses resultados não permitem construir conclusões mais precisas sobre as práticas de uso de fontes dos pesquisadores experientes, já que, como estudo exploratório, este trabalho abarca um número relativamente restrito de textos. Esses resultados devem ser vistos muito mais como indícios das práticas desses pesquisadores e de sua cultura disciplinar. Fica, assim, o desafio de desenvolvermos investigações utilizando um corpus mais ampliado e que dê conta de outras áreas do conhecimento e de outros contextos disciplinares e de diferentes veículos/espaços de divulgação do conhecimento, para que possamos construir compreensões mais profundas a respeito de como pesquisadores experientes dialogam com fontes no que diz respeito aos aspectos recortados para investigação.

Parece-nos fundamental, portanto, sublinhar a necessidade de mais investimentos de pesquisa nesse campo de estudos, focalizando inclusive as práticas de estudantes de graduação e de pós-graduação, a considerar a importância que, nessa era digital marcada por uma avalanche de conteúdos de fácil acesso - nem sempre confiáveis e relevantes - o diálogo com as fontes de pesquisa pode desempenhar na qualidade da escrita de textos científicos. 
V. $10(2)$

1-18 maio-ago 2020

\section{Referências}

ALVES, W. M.; BESSA, J. C. R. Orientações para escrita da redação do ENEM em vídeos do Youtube. Hipertextus Revista Digital, v. 19, p. 1-23, 2018.

ANDRÉ, M. E. D. A. de. Etnografia da prática escolar. 6. ed. Campinas: Papirus, 1995.

BATTESTIN, C.; DUTRA, J. C. Aonde vamos com tanta pressa? Os entraves do produtivismo acadêmico. Diálogo das Letras, v. 8, n. 2, p. 2-17, 2019.

BAZERMAN, C. El descubrimento de la escritura acadêmica. In: NAVARRO, F. (Coord.). Manual de escritura para carreras de humanidades. Ciudad Autónoma de Buenos Aires: Editorial de la Facultad de Filosofía y Letras Universidad de Buenos Aires, 2014. p. 11-16.

BERNARDES, S. M. F. D.; CATELÃO, E. de M. Tecnologias da informação e comunicação: transformando nossos hábitos institucionais de ensinar e aprender. Diálogo das Letras, v. 5, n. 2, p. 266-283, 2016.

BERNARDINO, R. A. dos S.; NASCIMENTO, D. P.; QUEIROZ, L. S. Estratégias de parafraseamento nas retomadas não literais do discurso alheio em texto acadêmico. In: SILVA, F. V.; OLIVEIRA, H. A. G. (org.). A escrita no ensino superior: saberes, métodos e gêneros. São Carlos: Pedro e João, 2018. p. 109-140.

BESSA, J. C. R. Dialogismo e construção da voz autoral na escrita do texto científico de jovens pesquisadores. 2016, $385 \mathrm{f}$. Tese (Doutorado em Linguística e Língua Portuguesa) - Universidade Estadual Paulista "Júlio de Mesquita Filho", Araraquara, 2016.

BESSA, J. C. R. Formas de presença da palavra alheia em artigos científicos de jovens pesquisadores. Revista Trama, v. 13, p. 143-178, 2017.

BESSA, J. C. R.; BERNARDINO, R. A. S. Equívocos em torno da escrita: o caso das dicas de produção de textos em vídeos do YouTube. Domínios de Lingu@gem, v. 11, p. 174, 2016.

BOCH, F. Former les doctorants à l'écriture de la thèse en exploitant les études descriptives de l'écrit scientifique. Linguagem em (Dis)curso, Tubarão, SC, v. 13, n. 3, p. 543-568, set./dez. 2013.

BURTON, V. T.; CHADWICK, S. A. Investigating the practices of student researchers: patterns of use and criteria for use of internet and library sources. Computers and Composition, v. 17, n. 3, p. 309-328, 2000.

COSCARELLI, C. V. A leitura em múltiplas fontes: um processo investigativo. Ensino e Tecnologia em Revista, v. 1, p. 67-79, 2017.

DEMO, P. 0 educador e a prática da pesquisa. Ribeirão Preto: Alphabeto, 2009.

DINIZ, D.; TERRA, A. Plágio: palavras escondidas. Brasília: Letras Livres; Rio de Janeiro: Editora Fiocruz, 2014.

ECO, U. Como se faz uma tese. Tradução de Gilson Cesar Cardoso de Souza. 25. ed. São Paulo: Editora Perspectiva, 2014. 
FINARDI, K. R.; FRANÇA, C. Oinglês na internacionalização da produção científica brasileira: evidências da subárea de Linguagem e Linguística. Intersecções, $v$. 9, n. 19, p.234-250, 2016.

FIORIN, J. L. Internacionalização da produção científica: a publicação de trabalhos de Ciências Humanas e Sociais em periódicos internacionais. Revista Brasileira de Pós-Graduação, v. 4, n. 8, 11, p. 263-281, 2007.

GOLDMAN, S. R. et al. Comprehending and learning from Internet sources: processing patterns of better and poorer learners. Reading research quarterly, v. 47, n. 4, $356-38,2012$.

HYLAND, K. Writing in the disciplines: research evidence for specificity. Taiwan International ESP Journal, v. 1, n. 1, p. 5-22, 2009.

HOWARD, R. M., SERVISS, T.; RODRIGUE, T. K. Writing from sources, writing from sentences. Writing and Pedagogy, v. 2, p. 177-192, 2010.

JAMIESON, S. The evolution of the Citation Project: lessons learned from a multi-year, multi-site study. In: SERVI, T.; JAMIESON, S. (eds.). Points of departure: rethinking student source use and writing studies research methods. Utah: Utah State University Pres, 2018, p. 33-61.

KERSCH, D. F.; MARQUES, R. G. Redes sociais digitais na escola: possibilidades de conexão, produção de sentido e aprendizagem. Diálogo das Letras, v. 6, n. 2, p. 343-362, jul./dez. 2017.

LAVILLE, C.; DIONNE, J. A construção do saber: manual de metodologia da pesquisa em ciências humanas. Tradução de Heloísa Monteiro e Francisco Settineri. Belo Horizonte: Editora UFMG, 1999.

LATOUR, B. Ciência em ação: como seguir cientistas e engenheiros sociedade afora. São Paulo: Editora UNESP, 2000.

LEFFA, V. J. As tecnologias digitais e seus enigmas: uma entrevista com Vilson Leffa. Entrevista realizada por Raquel Recuero e Francisco Vieira da Silva. Diálogo das Letras, v. 0, n. 2, p. 363-368, jul./dez. 2017.

MCCLURE, R; CLINK, K. How do you know that? An investigation of student research practices in the digital age. Libraries and the Academy, v. 9, n.1, p. $115-132,2009$.

MORAN, J. M. Como utilizar a internet na educação. Ci. Inf. v. 26 n. 2, p. 1-8, 1997.

MOTTA-ROTH, D.; HENDGES, G. R. Produção textual na universidade. São Paulo: Parábola Editorial, 2010.

NAVARRE, M. Penser par soi-même. Apresentação de dossiê. Sciences humaines, n. 323, mar. 2020. Disponível em: https://www.scienceshumaines. com/penser-par-soi-meme_fr_41968.html.Acesso em: 20 fev. 2020.

PECORARI, D. Good and original: plagiarism and patchwriting in academic second-language writing. Journal of Second Language Writing,v. 12, p. 317$345,2003$. 
V. $10(2)$

1-18 maio-ago 2020

PECORARI, D. Visible and occluded citation features in postgraduate second language writing. English for Specific Purposes, v. 25, p. 4-29, 2006.

PECORARI, D. Writing from sources, plagiarism and textual borrowing. In: MACHON, R. M. MATSUDA, P. K. (eds.). Handbook of Second and Foreign Language Writing. London: DeGruyter, 2015. p. 329-347.

PECORARI, D.; PETRIĆ, B. Plagiarism in second-language writing. Language Teaching, v. 47, n. 3, p.269-302, jul.2014.

PEREIRA, M. G. A introdução de um artigo científico. Epidemiol. Serv. Saúde, Brasília, v. 21, n. 4, p. 675-676, 2012.

PINTO, M. G. L. C. O labor da escrita: uma prática também testemunhada por estudantes. Diálogo das Letras, v. 7, n. 3, p. 10 - 29, set./dez. 2018.

RODRIGUE, T. K. Digital reading: Genre awareness as a tool for reading comprehension. Pedagogy, v.17, n. 2, p. 235-257, 2017.

SANCHEZ, C. A; WILEY, J.; GOLDMAN, S. R. Teaching students to evaluate source reliability during Internet research tasks. In: BARAB, S. A; HAY, K. E.; HICKEY, D. T. (eds.). Proceedings of the seventh international conference on the learning sciences. Bloomington, International Society of the Learning Sciences, 2006. p. 662-666.

VOLPATO, G. Dicas para redação científica. 3. ed. São Paulo: Cultura Acadêmica, 2010. 